\title{
ZIELEŃ NA ELEWACJACH - PROBLEM CZY KORZYŚĆ DLA BUDYNKU?
}

\author{
Justyna Janiak ${ }^{凶}$ \\ Wydział Budownictwa, Mechaniki i Petrochemii, Politechnika Warszawska, Płock
}

\begin{abstract}
STRESZCZENIE
Zieleń na elewacjach, mimo coraz większej popularności, wciąż budzi wiele wątpliwości odnośnie jej wpływu na ściany budynku. Czy rośliny pokrywające elewacje to rosnący problem, czy wsparcie zabudowy przez naturę? Niniejszy artykuł przedstawia i analizuje korzyści i problemy wynikające z połączenia architektury z naturą oraz ocenia konsekwencje jej zastosowania dla budynku. W rozważaniach uwzględniono stosowane powszechnie sposoby integracji roślin z elewacjami (system bezpośredni, pośredni i system żyjącej ściany), które przeanalizowano pod kątem dwóch rodzajów zachodzącego oddziaływania: fizycznego oraz chemicznego. Przegląd wskazał na liczne korzyści dla budynku wynikające z zastosowania zieleni, w tym ograniczenie strat ciepła, zwiększoną trwałość obudowy czy zmniejszenie naprężeń termicznych w przegrodzie pionowej. Mimo potencjalnych problemów wynikających głównie z erozyjnego działania roślin pnących porastających mury oraz ryzyka zawilgocenia osłoniętych elementów, zieleń stanowi wartość dodaną dla budynku.
\end{abstract}

Słowa kluczowe: zieleń, wertykalne systemy zieleni, zielone elewacje, roślinność w budownictwie, ściany zielone

\section{WSTĘP}

Zieleń na budynkach jest dobrze znanym rozwiązaniem zakorzenionym $\mathrm{w}$ historii i tradycji ${ }^{1}$, które w obecnych czasach przeżywa swój renesans. Po systemy integrujące rośliny i architekturę coraz chętniej i śmielej sięgają projektanci i inwestorzy, również w Polsce ${ }^{2}$. Mariaż natury ze współczesną architekturą zyskał na znaczeniu szczególnie na obszarach silnie zurbanizowanych. W zwartej tkance miejskiej, gdzie głównie z powodów ekonomicznych dąży się do maksymalnego zabudowania terenu, coraz częściej jedynym rozwiązaniem pozwalającym na wprowadzenie zieleni jest wykorzystanie elewacji i dachów budynków jako powierzchni biologicznie czynnych. Obecność roślinności w różnej formie w przestrzeni miejskiej jest nie tylko zasadna, ale w dobie postępującej degradacji środowiska życia człowieka wręcz

\footnotetext{
${ }^{1}$ Na przestrzeni wieków często wykorzystywano zieleń w rozwiązaniach architektonicznych począwszy od wiszących ogrodów Babilonu, które uważa się za najstarszy przykład integrujący rośliny i budynek (datowane na VI-VII w. p.n.e.), po powszechnie stosowane do XIX wieku zielone dachy w tradycyjnych zabudowaniach w Skandynawii.

${ }^{2}$ W Polsce rocznie buduje się około 0,5 miliona $\mathrm{m}^{2}$ zielonych dachów (Kowalczyk, 2011 za: Piątek-Kożuchowska, 2011). Coraz więcej jest również projektów i realizacji, w których zieleń pojawia się na ścianach budynków m.in. w Warszawie: budynek Biblioteki Uniwersytetu Warszawskiego, gmach Sądu Najwyższego, siedziba Fundacji na rzecz Nauki Polskiej, budynek biurowy
} Cristal Park.

凶Justyna.Janiak@pw.edu.pl 
wskazana. Na przestrzeni lat przeprowadzono wiele badań dotyczących różnych funkcji roślin w otoczeniu zurbanizowanym, m.in. w zakresie wpływu na jakość oraz czystość powietrza (Skorupski, 1984), wykorzystania zieleni jako izolacji akustycznej budynków (Azkorra i in., 2015) czy zagadnienia związane z psychologicznym oddziaływaniem elementów natury na człowieka (Szczepanowska, 2012 za: Dichter 1976). Wnioski z tych opracowań wskazują na pozytywne znaczenie roślinności nie tylko dla mikroklimatu i klimatu miasta, ale również dla jego mieszkańców. Coraz głośniej mówi się również o istotnym wpływie zieleni porastającej ściany na ograniczenie zapotrzebowania energii na ogrzewanie lub chłodzenie budynków ${ }^{3}$, co wpisuje się w panujący paradygmat zrównoważonego rozwoju.

Stosunkowo mniej uwagi poświęcono do tej pory oddziaływaniu systemów roślinnych na budynek. Jednym $\mathrm{z}$ głównych opracowań poruszających stricte zagadnienia związane $\mathrm{z}$ integracją elementów architektonicznych oraz roślinnych jest monografia Celadyna z 1992 roku. Opracowanie przybliża m.in. konsekwencje dla budynków wynikające z oddziaływania systemów roślinnych oraz zawiera analizę zjawisk powstajacych ze zbliżenia natury ze sztucznym środowiskiem zabudowań. Na znaczenie technicznej roli różnych form zieleni wspierającej budynek zwracają uwagę również m.in. Bartnicka i Ullman (2009), Kowalczyk (2011) oraz Zinowiec-Cieplik (2017), przytaczając możliwości wykorzystania zieleni jako izolacji termicznej, akustycznej czy nawet przeciwpożarowej. Wiele opublikowanych badań dostarcza również cennych danych, np.: temperatury powierzchni ściany zewnętrznej pokrytej roślinnością (Cuce, 2016), stopnia ograniczenia zapotrzebowania na energię do ogrzewania i chłodzenia budynku uzyskanej dzięki zieleni na elewacjach (Perini, Ottelë, Haas i Raiteri, 2011) czy zmniejszenia prędkości wiatru przy ścianie porośniętej roślinami (Perini, Ottelë, Fraaij, Haas i Raiteri,
2011). Mimo to nadal w powszechnej opinii wertykalna zieleń na elewacjach, chociaż wizualnie atrakcyjna, postrzegana jest jako potencjalne źródło problemów. Obawy związane są nie tylko z pielęgnacją roślin, ale z możliwością dezintegracji zewnętrznej powierzchni ścian, szczególnie w przypadku pnączy bezpośrednio porastających mury. Czy rzeczywiście ten sceptycyzm wobec zielonych rozwiązań jest uzasadniony? Czy dla ścian zewnętrznych wskazane jest sięganie po rozwiązania wykorzystujące zieleń pomimo różnych konsekwencji wynikających z integracji elementów roślinnych $\mathrm{z}$ budowlanymi?

W niniejszym artykule podjęto się oceny wpływu zieleni na elewację budynku poprzez analizę wertykalnych systemów roślinno-architektonicznych przeprowadzoną dla jej nadziemnej części według dwóch głównych rodzajów zachodzącego oddziaływania: fizycznego oraz chemicznego. Najpierw jednak przybliżono dwa istotne czynniki, które wpływają na relacje między elementami w ramach rozpatrywanego układu, tj. sposób wprowadzenia zieleni na ściany budynku oraz jej parametry warunkujące intensywność oddziaływania.

\section{KLASYFIKACJA SYSTEMÓW ROŚLINNO- -ARCHITEKTONICZNYCH}

W systemach integrujących zieleń z budynkami czynnikiem determinującym jest sposób wprowadzenia roślin na elewacje. W stosowanych obecnie rozwiązaniach wyróżnić można dwa główne kierunki: tradycyjne zielone fasady i wciąż zyskujące na popularności tzw. żyjące ściany (Barnaś, 2011; Perini i in., 2011a; Pérez, Coma, Martorell i Cabeza, 2014; Cuce, 2016). W przestrzeniach miejskich często stosowane są wertykalne systemy zieleni wykorzystujące różnego rodzaju konstrukcje wsporcze, jak np. w budynku Biblioteki Uniwersytetu Warszawskiego (rys. 1). Zieleń w tym projekcie stanowi istotną część architektury budynku,

\footnotetext{
${ }^{3}$ Oszczędności z tytułu mniejszego zużycia energii na klimatyzację wnętrz w porównaniu do ściany bez zieleni mogą sięgać: do 50\% (Celadyn, 1992), 50-70\% (Trzaskowska, 2010) czy w klimacie śródziemnomorskim w zależności od ściany zewnętrznej i rodzaju zielonej fasady od 1,4 do 65,8\% (Perini i Rosasco, 2013). Zapotrzebowanie na energię potrzebną do ogrzewania budynku może być zminimalizowane o 25\% (Sheweka i Mohamed, 2012).
} 


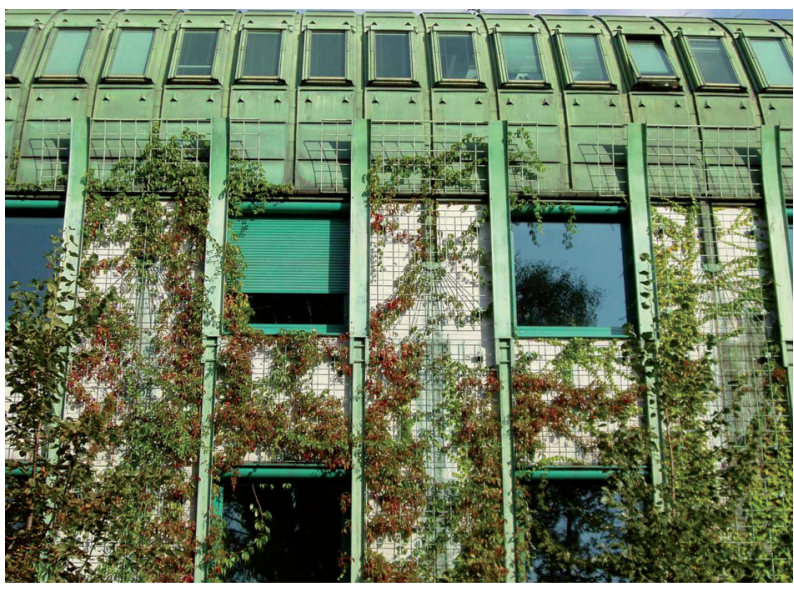

Rys. 1. Fragment elewacji budynku Biblioteki Uniwersytetu Warszawskiego jako przykład integracji zieleni $\mathrm{i}$ architektury w systemie bezpośrednim, tj. wykorzystania konstrukcji wsporczych dla roślin (źródło: www.mbarch.pl; dostęp 27.10.2018)

Fig. 1. Fragment of the façade of the Library of the University of Warsaw as an example of integration of greenery and architecture in the direct system, i.e. the use of support structures for plants (source: www.mbarch.pl; access 27.10.2018)

porastając stelaże zarówno zamocowane do elewacji, jak i te znajdujące się wewnątrz obiektu, ale w miarę upływu czasu również pozostałe powierzchnie fasady. Muzeum przy ul. Quai Branly w Paryżu jest znaną realizacją systemu tzw. żyjącej ściany w technologii Patricka Blanca, uważanego za prekursora wertykalnych ogrodów (rys. 2). Rozwiązanie to jest przykładem najdalej posuniętej integracji elewacji z zielenią, gdzie roślinność zakorzeniona jest w medium, które jest zamocowane do stelaża nośnego.

Ponadto w ramach tych systemów ze względu na technologię, konstrukcję czy charakter oddziaływania na siebie części składowych układu wyróżnić można wiele podtypów (rys. 3). W niniejszym opracowaniu powołano się na systematykę zaproponowaną przez Manso i Castro-Gomesa (2015).

Poszczególne rozwiązania systemowe cechuje m.in. różny poziom odizolowania zieleni od płaszczyzny elewacji oraz odmienny stopień możliwości kontroli roślinności. W kontekście rozpatrywanego

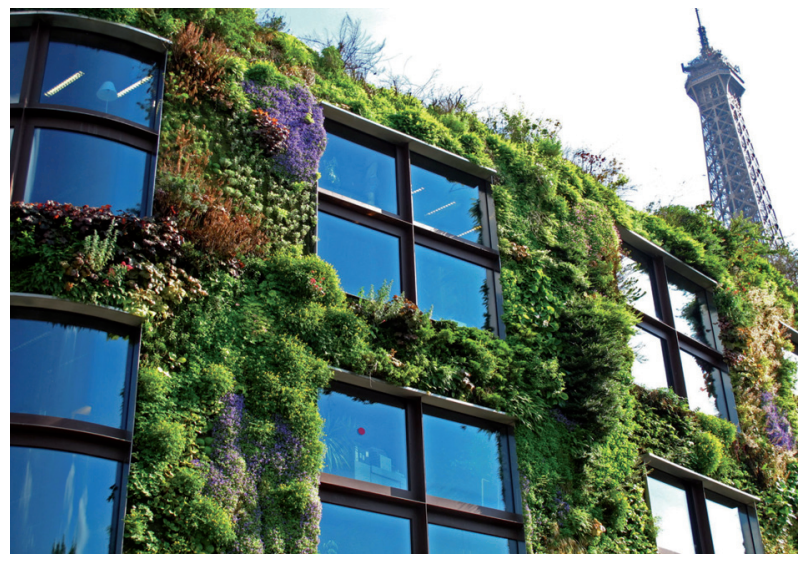

Rys. 2. Budynek Muzeum przy ul. Quai Branly w Paryżu autorstwa Jeana Nouvela z elewacją w systemie tzw. żyjącej ściany według Patricka Blanca (źródło: verticalgardenpatrickblanc.com; dostęp 27.10.2018).

Fig. 2. Museum Quai Branly building in Paris by Jean Nouvel of integration of greenery and architecture in by Patrick Blanc in the direct system, i.e. the use (source:verticalgardenpatrickblanc.com of support structures for plants; access 27.10.2018)

problemu są to dwa główne czynniki, które w istotny sposób wpływają na poziom oddziaływania roślin na przegrodę zewnętrzną. Wybór konkretnej technologii może ograniczać lub sprzyjać dynamice procesów i relacji zachodzących pomiędzy elementami zielonymi a budowlanymi. Przykładowo tradycyjne zielone fasady z pnączami swobodnie anektującymi powierzchnie elewacji są rozwiązaniami, które w większym stopniu utrudniają kontrolę roślin niż uporządkowane moduły tzw. żyjących ścian. Oczywiście w głównej mierze wynika to ze specyfiki roślinności, której parametrami nie sposób sterować. Jednak można wybrać rozwiązania, które umożliwią jej kontrolę w pewnym zakresie, dzięki czemu łatwiej wpłynąć na sposób i charakter oddziaływania zieleni na ściany zewnętrzne oraz osiągnąć pożądany efekt. $\mathrm{W}$ tabeli 1 przedstawiono ocenę głównych podtypów zielonych elewacji ze względu na możliwość dynamicznego zachowania roślinności oraz jej nadzorowania wewnątrz układu. Zestawienie wskazuje na żyjące ściany jako na system, który 


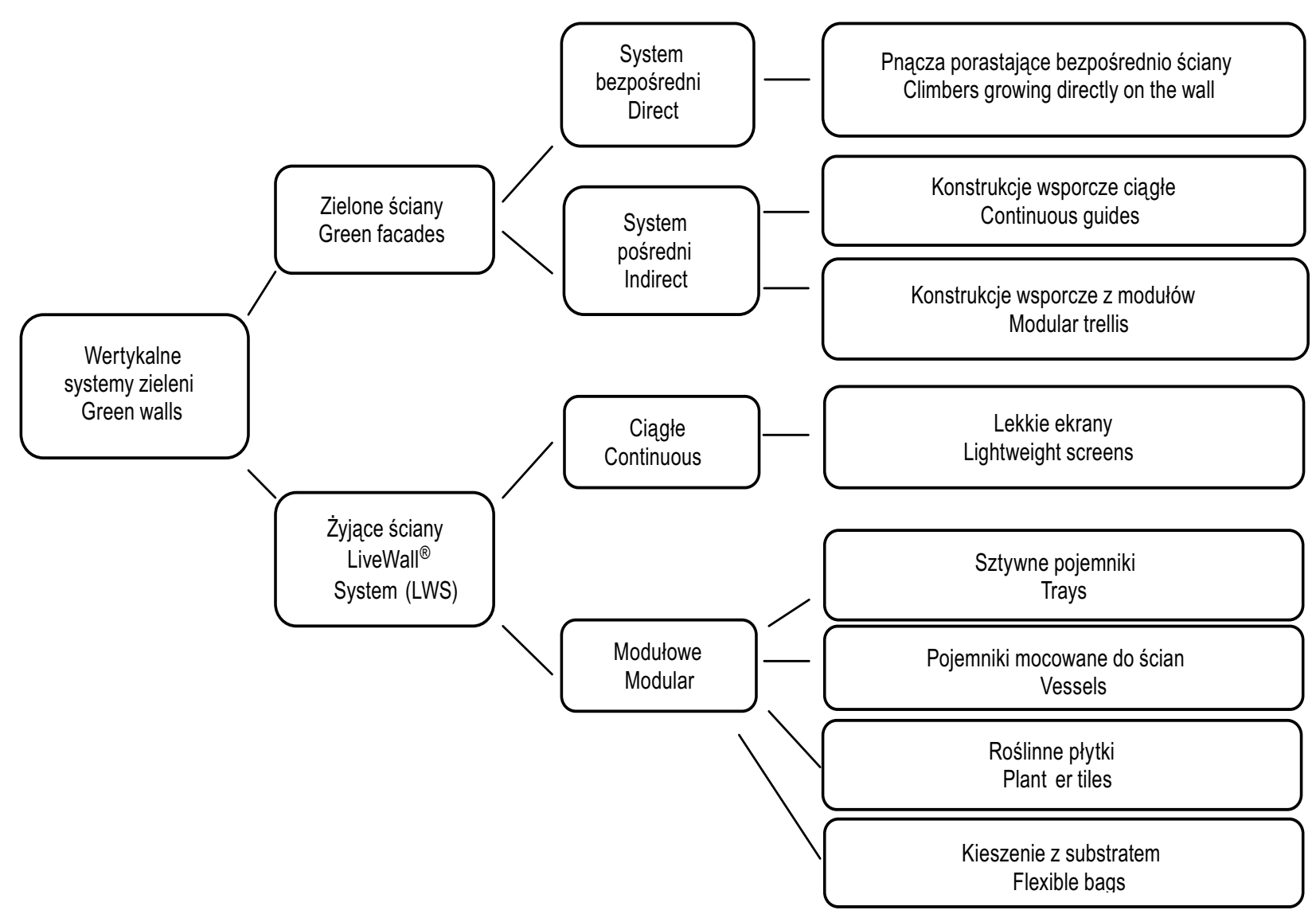

Rys. 3. Klasyfikacja wertykalnych systemów zieleni według systematyki Manso i Castro-Gomes (2015)

Fig. 3. Classification of vertical greenery systems according to systematics introduced by Manso and Castro-Gomes (2015)

najbardziej ogranicza spontaniczny charakter relacji w jego ramach.

Równie istotny dla oddziaływania zieleni na powierzchnie ścian jest wspomniany stopień jej autonomii wobec elewacji. W systemach oferujących większą niezależność elementy układu są względem siebie w pewnej odległości, w której zachodzi przede wszystkim oddziaływanie fizyczne. Takie rozwiązanie zastosowano w budynku centrum handlowego Sihlcity w Zurychu dla zielonej ściany o powierzchni ponad $580 \mathrm{~m}^{2}$ (rys. 4). Konstrukcja wsporcza dla pnączy w postaci stelaża z pionowych i poziomych lin ze stali nierdzewnej została za pomocą elementów dystansowych wysunięta $70 \mathrm{~cm}$ przed elewację, co umożliwiło m.in. na swobodny rozwój roślin.
W systemach o większym stopniu integracji rośliny i zewnętrzna powierzchnia elewacji pozostają w bezpośrednim kontakcie i mogą wywierać na siebie akcję mechaniczną, chemiczną, a także intensywniejszą fizyczną (Celadyn, 1992), jak ma to miejsce na zewnętrznych ścianach budynku mieszkalnego projektu Friedensreicha Hunderwassera w Wiedniu (rys. 5). Oryginalną architekturę tego obiektu swobodnie porastają różnego rodzaju formy zieleni. W ramach poszczególnych podtypów skala oddziaływania może być różna w zależności od zastosowanych konstrukcji wsporczych i jej odległości od elewacji, materiałów, orientacji budynku względem stron świata, sposobu irygacji i czynników niezależnych, tj. roślin, warunków klimatycznych. 
Janiak, J. (2019). Zieleń na elewacjach - problem czy korzyść dla budynku? Acta Sci. Pol. Architectura 18 (1), 119-132, DOI: 10.22630/ASPA.2019.18.1.14

Tabela 1. Weryfikacja możliwości kontroli oddziaływania zieleni na budynek w zależności od dynamiki procesów zachodzących w różnych rozwiązaniach systemowych. (opracowanie własne)

Table 1. Verification of the possibility of controlling the impact of greenery on the building depending on the dynamics of processes taking place in various system solutions (own elaboration)

\begin{tabular}{|c|c|c|c|}
\hline $\begin{array}{l}\text { Rodzaj systemu } \\
\text { Type of system }\end{array}$ & $\begin{array}{l}\text { Podtyp } \\
\text { Subtype }\end{array}$ & $\begin{array}{c}\text { Dynamika procesów } \\
\text { i relacji w ramach systemu } \\
\text { Dynamics of processes and relations within } \\
\text { the system }\end{array}$ & $\begin{array}{l}\text { Kontrola w ramach systemu } \\
\text { Control within the system }\end{array}$ \\
\hline & $\begin{array}{l}\text { Bezpośredni: bluszcz (Hedera helix) } \\
\text { porastający ceglany mur - Direct: ivy } \\
\text { (Hedera helix) growing on brick wall }\end{array}$ & $\begin{array}{l}\qquad+++ \\
\text { Intensywny charakter relacji wynikający z } \\
\text { bezpośredniego kontaktu roślin ze ścianą } \\
\text { - Intense nature of relationship resulting } \\
\text { from the direct contact of plants with walls }\end{array}$ & $\begin{array}{l}+ \\
\text { Spontaniczny rozwój roślin na powi- } \\
\text { erzchni ścian - Spontaneous development } \\
\text { of plants on the surface of walls }\end{array}$ \\
\hline $\begin{array}{l}\text { Zielone fasady } \\
\text { Green facades }\end{array}$ & $\begin{array}{l}\text { Pośredni: rośliny pnące na konstruk- } \\
\text { cji wsporczej, np. elewacja Biblioteki } \\
\text { Uniwersytetu Warszawskiego - Indirect: } \\
\text { creepers on supporting structure ex. the } \\
\text { elevation of the Library of the University } \\
\text { of Warsaw }\end{array}$ & $\begin{array}{l}\text { Charakter relacji zależy od odległości kon- } \\
\text { strukcji wsporczej od ściany i ewentualnej } \\
\text { ekspansji roślin na powierzchnie elewacji } \\
\text { poza stelażem - The nature of relation- } \\
\text { ship depends on the distance of supporting } \\
\text { structure from the wall ant the possible } \\
\text { expansion of plants on the façade's surface } \\
\text { outside the frame. }\end{array}$ & $\begin{array}{l}\text { Rozwój zieleni ograniczony do miejsc } \\
\text { wyznaczonych przez konstrukcje wspor- } \\
\text { cze. Możliwość wyznaczenia stref zieleni } \\
\text { - Development of greenery limited to } \\
\text { the places designated by the supporting } \\
\text { structure. The possibility of determining } \\
\text { green zones }\end{array}$ \\
\hline $\begin{array}{l}\text { Żyjące ściany } \\
\text { LiveWall }^{\circledR}\end{array}$ & $\begin{array}{l}\text { Żyjąca ściana według technologii } \\
\text { Patricka Blanca - Patrick Blanc's green } \\
\text { wall solution }\end{array}$ & $\begin{array}{l}+ \\
\text { Ograniczona przez warstwową budowę } \\
\text { sytemu żyjącej ściany - Limited by the lay- } \\
\text { ered construction of the living wall system }\end{array}$ & $\begin{array}{l}\text { Rozwój zieleni ograniczony do miejsc } \\
\text { wyznaczonych w projekcie. Możliwość } \\
\text { wymiany części roślin bez uszczerbku } \\
\text { dla całego systemu - Development of } \\
\text { greenery limited to the places designated } \\
\text { in the project. The possibility of replacing } \\
\text { parts of plants without damage to the } \\
\text { entire system }\end{array}$ \\
\hline
\end{tabular}

Znak +++ wskazuje na wzmożony stopień kontroli lub szczególnie intensywny charakter relacji - The sign +++ indicates an increased level of control or a particularly intense nature of relationship.

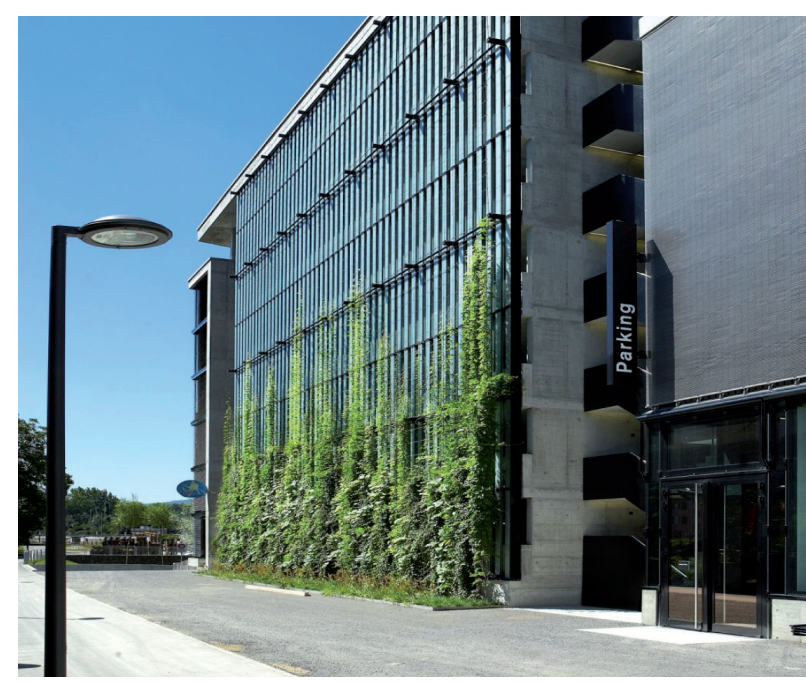

Rys. 4. Odsunięta konstrukcja wsporcza dla zieleni pnącej na elewacji budynku Sihl City w Zurychu projektu Theo Hotza (źródło: www.green-walls.co.uk; dostęp 24.10.2018)

Fig. 4. Recoiled support structure for the climbing plants on the façade of Sihl City building in Zurich, designed by Theo Hotz (source: www.green-walls. co.uk; access 24.10.2018)

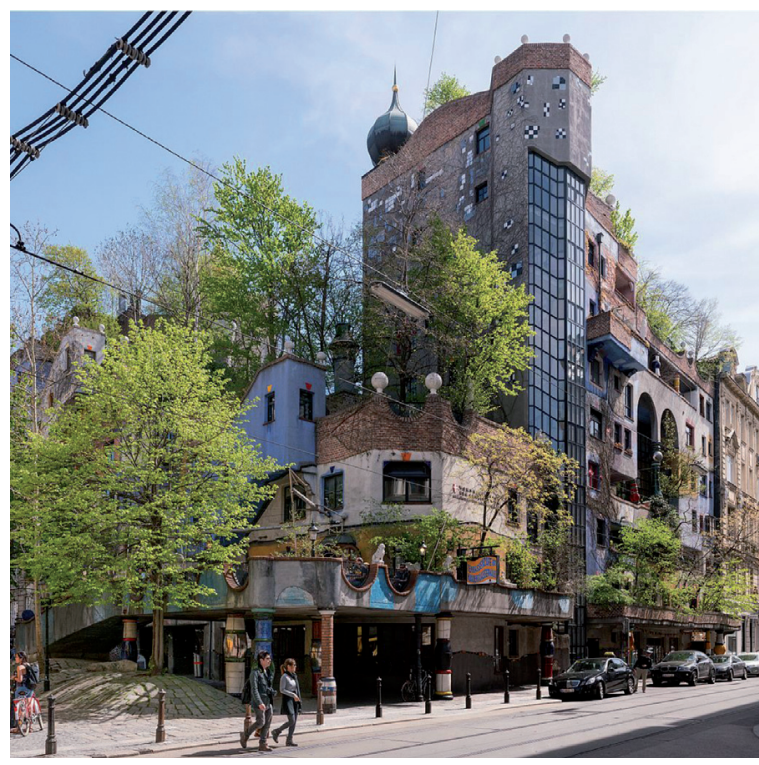

Rys. 5. Zieleń na zabudowie mieszkalnej według projektu Friedensreicha Hunderwassera we Wiedniu (źródło:de.wikipedia.org; dostęp 24.10.2018)

Fig. 5. Greenery on a residental development in Vienna designed by Friedensreich Hundertwasser (source: de.wikipedia.org; access 24.10.2018) 


\section{PARAMETRY ZIELENI}

W każdym z obecnie stosowanych systemów roślinno-architektonicznych warunkiem niezbędnym funkcjonowania układu jest zapewnienie optymalnej formy wybranej zieleni. Kondycja roślin wpływa na stopień oddziaływania na przegrody pionowe budynku i w znacznej mierze jest uwarunkowana przez dobór gatunku i jego cechy charakterystyczne, takie jak: wiek, dostęp do światła, wody i składników odżywczych, odporność na niekorzystne warunki panujące w środowisku zurbanizowanym (kwaśne deszcze, wilgotność i zanieczyszczenie powietrza), klimat oraz ekspozycję porośniętej ściany. Te wszystkie czynniki wpływają na prawidłowy wzrost roślin, gęstość pokrywy, masę liści oraz stopień pokrycia porośniętych powierzchni. W przypadku systemów żyjących ścian, szczególnie w klimacie umiarkowanym, wybór odpornych na wahania temperatury roślin oraz zapewnienie odpowiedniego medium stanowi wyzwanie. Niekiedy jak w budynku Fundacji na rzecz Nauki Polskiej konieczne okazuje się monitorowanie kondycji zieleni oraz systematyczna wymiana na bardziej odporne na warunki klimatyczne gatunki roślin. Optymalny rozwój roślinności ma bezpośrednie przełożenie na skalę oddziaływania elementu żywego na budowlany. Stąd ważnym parametrem w badaniach nad wpływem roślin na budynek jest wskaźnik $L A I$ (ang. leaf area index) opisujący całkowitą powierzchnię liści na jednostkę powierzchni ${ }^{4}$. Im wyższy indeks LAI, tym bardziej gęste jest listowie, a tym samym roślina skuteczniej pokrywa fasadę budynku ${ }^{5}$. W osłonie przeciwsłonecznej istotnym parametrem jest także chłonność liścia, która określa część radiacji słonecznej zaabsorbowanej przez jego powierzchnię czy wskaźnik tłumienia promieniowania. Kluczowy jest również rozmiar elementów roślinnych, w tym grubość listowia oraz powierzchnia pokrycia elewacji. Różnice w parametrach zieleni wpływają na mniejszą lub większą intensywność oddziaływania na powierzchnię muru na fizycznym i chemicznym poziomie.

\section{ODDZIAŁYWANIE FIZYCZNE}

W konfiguracji wzajemnego zbliżenia roślin i architektury istnieje możliwość wywierania akcji mechanicznej przez żywy element układu, który dąży do ekspansji wzrostowej, szukając optymalnych dla siebie warunków. Skala oddziaływania na przegrody zewnętrze zależy od różnych czynników, począwszy od wyboru gatunku roślin oraz sposobu ich integracji z budynkiem, rozwiązań architektoniczno-materiałowych ścian po warunki klimatyczne panujące w danej lokalizacji. Najczęściej negatywny wpływ zieleni na powierzchnię elewacji przypisuje się bezpośrednio porastającym je pnączom, np. bluszczowi pospolitemu (Hedera helix), który potrafi skutecznie wykorzystać nawet mikropęknięcia powierzchni, powodując deteriorację materiału. Należy jednak zauważyć, że w niektórych badaniach nie zaobserwowano negatywnego oddziaływania pnączy przy elewacjach w dobrym stanie technicznym (Celadyn, 1992) czy np. na elewacjach z wielkiej płyty w budynkach w Niemczech (Borowski, 1996). Co więcej, istnieje wiele przykładów wiekowych obiektów w dobrym stanie, które zdaje się przetrwały próbę czasu mimo, a może właśnie dzięki, pokrywającym je pnączom, np. budynek szkolny sióstr nazaretanek w Warszawie przy ul. Czerniakowskiej czy gmach Muzeum Narodowego we Wrocławiu porośnięty winobluszczem.

Dla analizy oddziaływania mechanicznego elementu roślinnego na architektoniczny istotne jest również uwzględnienie sposobu mocowania konstrukcji wsporczej do ściany oraz powierzchnia styku tych dwóch elementów. W systemie bezpośrednim, tj. ściany zintegrowanej z pnączem, połączenie następuje punktowo za pomocą przylg i korzonków czepnych, które zazwyczaj nie stanowią dużego obciążenia ze względu na znaczną liczbę punktów i stosunkowo niewielki ciężar (Celadyn, 1992). Dzięki temu przy obecnie stosowanych materiałach budowlanych, rośliny te nie są zagrożeniem dla trwałości obudowy budynku. Wyjątek mogą stanowić niezwykle rozbudowane sys-

\footnotetext{
${ }^{4} \mathrm{~W}$ niektórych publikacjach na temat zielonych ścian zamiast wskaźnika $L A I$ pojawia się bardziej precyzyjne określenie WLAI (ang. wall leaf area index).

${ }^{5}$ Przykładowo można uzyskać redukcję temperatury powierzchni ściany z zielenią o $0,8^{\circ} \mathrm{C}$ przy $L A I=0$, a przy $L A I=4$ obniżenie może wynieść $13,1^{\circ} \mathrm{C}$ (Susorova, Angulo, Bahrami i Stephens, 2013).
} 
temy zieleni o dużej powierzchni ${ }^{6}$ porastające elewacje o złym stanie technicznym, np. z obluzowanymi panelami lub przy tynku o słabej przyczepności do muru. Problem stanowią również zamontowane na budynku rynny, anteny, piorunochrony czy innego rodzaju instalacje techniczne, które pod presją intensywnej ekspansji wzrostowej niektórych gatunków mogą ulec uszkodzeniu, a nawet zerwaniu. Na penetrację roślin pnących szczególne narażone są elementy systemu odprowadzającego wodę $\mathrm{z}$ dachu, tj. rynny i rury spustowe, które pozbawione należytej konserwacji obrastając zielenią, często tracą drożność.

Tego rodzaju negatywne oddziaływanie jest znacznie ograniczone w przypadku wprowadzenia dodatkowej konstrukcji wsporczej dla roślin (systemy pośrednie), która może być zintegrowana lub niezależna od ścian w formie np. rozpiętych, stalowych linek lub sztywnych podpór z metalowych prętów. W każdym z rozwiązań konstrukcja wsporcza odciąża cała powierzchnię ściany, przenosząc obciążenia punktowo w miejscach jej zamontowania. Siła oddziaływania zależy głównie od planowanej wielkości zieleni, od ilości i rozstawu miejsc montażu podparcia, a także od takich czynników jak deszcz, śnieg czy wiatr. W przypadku wysokich ścian o bardzo rozwiniętych systemach roślinnych istotne stają się oddziałujące na nie poziome sily ssące przy silnych wiatrach (Celadyn, 1992), szczególnie w wypadku znacznego odsunięcia konstrukcji wsporczej. Zachowanie dystansu między elementami układu roślinno-architektonicznego z kolei minimalizuje ryzyko porośnięcia i uszkodzenia elementów instalacji technicznych przez pnącza. Przykładem może być rozwiązanie autorstwa Arup Associates zastosowane w budynku Citi Data Centre we Frankfurcie, gdzie lokalizację zieleni ograniczono tyko do jednej dużej ściany wysokiej na $12 \mathrm{~m}$ i długiej na $55 \mathrm{~m}$, która jest oddzielnym elementem dostawionym do elewacji obiektu.

Tego rodzaju oddziaływanie praktycznie nie zachodzi w systemach żyjących ścian, a obciążenie takich rozwiązań zwiększone jest o ciężar medium, w którym zakorzenione są rośliny, tj. gleba, specjalna pianka, filc z pilśni, włóknina, warstwy izolacji przeciwwilgociowej, instalacje nawadniające czy kasetony. Obciążenie ściany wykonanej w systemie LivePanel ${ }^{\circledR}$ może wynieść $35-40 \mathrm{~kg} \cdot \mathrm{m}^{-2}$, przy założeniu, że jest wykonana $\mathrm{z}$ modułów o wymiarach $400 \times 400 \times 100 \mathrm{~mm}^{7} . \mathrm{Z}$ biegiem czasu przyrost roślin prowadzi do zwiększenia obciążenia dla przegród budynku, ale tym samym wpływa na efektywniejsze oddziaływanie roślin na parametry fizyczne ściany.

$\mathrm{Z}$ punktu widzenia fizyki budowli integracja roślin na ściany budynku jest korzystna, a nawet wskazana. Pionowa przegroda zewnętrza zyskuje dodatkową warstwę, która ochrania ją przed działaniem czynników zewnętrznych, takich jak: promieniowanie słoneczne, dobowe wahania temperatury na jej powierzchni, kwaśne deszcze, wiatr, woda opadowa czy zanieczyszczenia obecne w powietrzu. Efektywność osłaniającej roli systemów zależy od sposobu introdukcji zieleni na elewację, od rodzaju użytych roślin, w tym również od ich stanu oraz wieku, stopnia zazielenienia ścian, a także ekspozycji względem stron świata. Najkorzystniejszym rozwiązaniem jest żyjąca ściana z racji swojej warstwowej budowy, w której oprócz zieleni elementami wpływającymi na jej fizyczne parametry są także rodzaj i grubość substratu. Wertykalne systemy zieleni mogą przynieść wymierny efekt dla przedłużenia żywotności elewacji. Według Perini i Rosasco (2013) otynkowana ściana w zależności od jakości użytego materiału i warunków zewnętrznych (zanieczyszczenia powietrza itp.) wymaga renowacji po 25-30 latach, a wprowadzenie osłony roślinnej wydłuża ten okres o 15 lat przy założeniu właściwego utrzymania technicznego i biologicznego systemów zieleni.

\section{Ochrona przed słońcem}

Dłuższe zachowanie trwałości obudowy dzięki zieleni wynika przede wszystkim z ochrony przed intensywnym promieniowaniem słonecznym, szczególnie uciążliwym w ekspozycji zachodniej, wschodniej i południowej. Część promieniowania odbijana jest przez liście roślin, znaczna ilość absorbowana na potrzeby fotosyntezy, transpiracji, ewaporacji i respiracji, a tylko $5-30 \%$ pozostałego promieniowania dociera do powierzchni

\footnotetext{
${ }^{6}$ Winobluszcz pięciolistkowy pokrywający $531 \mathrm{~m}^{2}$ ściany osiąga wagę około $3 \mathrm{t}$ (Borowski, 1996).

${ }^{7}$ Dane dotyczą systemu firmy Mobilane UK (źródło: www.mmobilane.co.uk).
} 
muru (Perini i in., 2011a). Czyni to zieleń skutecznym ekranem blokującym słońce, zapewniając zacienianie na poziomie równym obecnie stosowanym rozwiązaniom przeciwsłonecznym w postaci: żaluzji, rolet czy markiz (Pérez i in., 2014 za: Stec, 2005) ${ }^{8}$. Dzięki zastosowaniu naturalnych ekranów przeciwsłonecznych ściana jest chroniona przed nadmiernym nagrzewaniem oraz dobowymi fluktuacjami temperatury nawet aż o $50 \%$ (Sheweka i Mohamed, 2012), co wpływa na zmniejszenie naprężeń termicznych w przegrodzie. Ukształtowana przez zieleń strefa buforowa przed elewacją również wpływa na zmniejszenie oddziaływania dużych, dobowych wahań temperatury na ścianę zewnętrzną. Rośliny zostały wykorzystane jako ochrona przed insolacją, np. w budynku biurowym Cristal Park w Warszawie. Najbardziej wyeksponowane na działanie promieniowania słonecznego segmenty budynku w części wschodniej i zachodniej zyskały osłonę w postaci pnączy porastających przygotowaną konstrukcję wsporczą ze stalowych lin. Stelaże pod roślinność o wysokości kondygnacji są odsunięte od przeszkolonych elewacji i zamontowane do betonowych gzymsów.

Liczne badania potwierdzaja potencjał roślin w ochładzaniu powierzchni elewacji, dzięki zarówno zacienianiu, jak i transpiracji ${ }^{9}$ (Sternberg, Viles i Cathersides, 2010; Perini i in., 2011a; Susorova i in., 2013; Hoelscher, Nehls, Jänicke i Wessolek, 2015; Cuce, 2016). Wpływ na obniżenie temperatury zależy od wielu czynników, głównie od: wybranego rozwiązania systemowego, rodzaju roślin, gęstości ich listowia, ekspozycji zielonej fasady, a także od wilgotności powietrza ${ }^{10}$, klimatu, warunków pogodowych czy albedo ścian11. Z przeprowadzonych badań wynika (Pérez i in., 2014), że zieleń wpływa na obniżenie temperatury powierzchni elewacji niezależnie od jej orientacji, przy czym największą redukcję odnotowa- no przy ekspozycji wschodniej i zachodniej. Ponadto efektywność roślinności w tym zakresie jest różna w ciągu dnia. Według Safikhani, Abdullah, Ossen i Baharvand (2014) skuteczność zieleni w obniżaniu temperatury powierzchni osłanianych elementów jest największa $\mathrm{w}$ porze popołudniowej przy najwyższej temperaturze powietrza. Oddziaływanie roślin na ściany budynku różni się także w zależności od lokalizacji budynku w strefie klimatycznej. Przykładowo badania przeprowadzone w Singapurze na ośmiu różnych rodzajach zielonych systemów pokazały maksymalne obniżenie temperatury powierzchni ściany o $11,58^{\circ} \mathrm{C}$ (Pérez i in., 2014 za: Wong i in., 2010). Podczas innych obserwacji w klimacie umiarkowanym w Nottingham na ścianie porośniętej zaledwie $10 \mathrm{~cm}$ warstwą bluszczu pospolitego (Hedera helix) zanotowano około $6^{\circ} \mathrm{C}$ spadek nawet podczas pochmurnych dni (Cuce, 2016). Ochrona przeciwsłoneczna, jaka zapewnia zielona fasada, przekłada się również na ograniczenie zapotrzebowania na energię niezbędną do ochłodzenia wnętrza budynku, szczególnie w klimatach gorących.

\section{Ochrona przed wodą deszczową i wilgocią}

Wprowadzenie zieleni na elewację obiektu minimalizuje również działanie wody deszczowej. Dzięki temu pionowa przegroda zewnętrzna nie jest bezpośrednio narażona na wpływ kwaśnych deszczy czy erozję wywołaną naprzemiennym zamakaniem i przesuszaniem powierzchni muru. Skuteczność ochrony ścian przed zawilgoceniem zależy przede wszystkim od wentylacji warstwy powietrznej pomiędzy elementem zieleni a budowlanym. Możliwość cyrkulacji powietrza sprzyja osuszaniu muru, który nawet szczelnie porośnięty roślinami może ulec zawilgoceniu. Kluczowa jest optymalna odległość zieleni od elewacji, która powinna być rozpatrywana indywidualnie,

\footnotetext{
${ }^{8}$ Badania przeprowadzono dla podwójnej zielonej fasady w klimacie śródziemnomorskim.

${ }^{9}$ Te dwa czynniki mają zasadnicze znaczenie dla obniżenia temp. powierzchni ścian. Według badań Hoelschera i in. (2015) udział zacieniania i transpiracji w ochłodzeniu przegród zewnętrznych budynku był różny w zależności od warunków pogodowych (zachmurzenie) i poziomu nawodnienia roślin i wskazywał na przeważającą rolę zacieniania $(87,81,5,79,4 \%)$, jednak w pochmurny dzień to transpiracja stanowiła $73 \%$ całego dziennego udziału w redukcji temperatury.

${ }^{10}$ Zieleń na elewacjach skuteczniej obniża temperaturę przy większej wilgotności powietrza, ponieważ jej wzrost sprzyja transpiracji szparkowej u roślin (Susorova i in., 2013).

${ }^{11}$ Przy wyższym albedo ścian odnotowano mniejsze różnice w temperaturach na powierzchni przegród uzyskane dzięki roślinności (Hoelscher i in., 2015).
} 
uwzględniając m.in. wybrane rośliny, rodzaj konstrukcji, mikroklimat miejsca czy zastosowane rozwiązania materiałowe. Inne czynniki, które wpływają na ochronę muru przed zawilgoceniem, to: pokrywa roślinna, a w szczególności jej powierzchnia, zwartość $\mathrm{i}$ budowa listowia, wyprofilowanie elewacji. $\mathrm{O}$ ile pnącza o dachówkowo ułożonych liściach w zwartej formie sprzyjają szybkiemu odprowadzeniu wody z powierzchni zielonej elewacji, o tyle geste poszycie zieleni może powodować również wzrost wilgotności, utrudniając ewaporację w szczelinie wentylacyjnej, szczególnie przy niedostatecznej cyrkulacji powietrza w tej strefie. Ponadto rośliny niezależnie od sposobu wprowadzenia ich na elewację generują wilgoć, która w systemach żyjących ścian (LWS) utrzymuje się dłużej ze względu na obecność substratu oraz instalacji nawadniającej (Safikhani i in., 2014).

Obawy związanie z ewentualnym powstaniem zawilgocenia w powszechnej opinii odnoszą się przede wszystkim do roślin, podczas gdy niemały udział ma samo ukształtowanie architektoniczne elewacji. Przykładowo brak wystajacych gzymsów, szczególnie $\mathrm{w}$ ścianach szczytowych pokrytych pnączami, jedynie w jej dolnej części zwiększa zawilgocenie pod warstwa zieleni ${ }^{12}$.

Zdolność zieleni do retencji wody nie powinna być rozpatrywana jedynie w kontekście potencjalnych trudności i zagrożeń związanych $\mathrm{z}$ zawilgoceniem ścian. Pnącza potrafią niezwykle intensywnie pobierać wodę ze swojego otoczenia, dążąc do odzyskania nawet śladowych ilości wilgoci ze ścian. Dzięki temu przyczyniają się $\mathrm{w}$ pewnym stopniu do osuszania muru, który porastają, ale jednocześnie mogą powodować erozję zewnętrznej warstwy elewacji. Rośliny, których system korzeniowy jest osadzony w gruncie, czerpiąc wodę z podłoża, działają jak pompa ssąco- -tłocząca, co może doprowadzić nawet do osuszenia fundamentów (Bartnicka i Ullman, 2009). Interesującym spożytkowaniem naturalnej tendencji roślin do retencji i chłonności wody jest wykorzystanie płaszcza zieleni jako dodatkowej izolacji ogniowej fasad (Zinowiec-Cieplik, 2017). Warunkiem niezbędnym jest utrzymanie pewnego minimalnego poziomu wilgotności warstwy zielonej, co potencjalnie można byłoby uzyskać w systemie żyjącej ściany.

\section{Ochrona przed wiatrem}

Osłaniająca rola zieleni, chroniąca elewację przed oddziaływaniem wiatru, ma niewielkie znaczenie dla trwałości obudowy zewnętrznej. W badaniach nie zaobserwowano również oddziaływania zielonych elewacji na odczuwaną prędkość wiatru w odległości $1 \mathrm{~m}$ od budynku (Perini i in., 2011b). Odnotowano jednak wpływ roślin na zmniejszenie prędkości wiatru w warstwie zielonego pokrycia oraz w szczelinie wentylacyjnej, w zależności od sposobu integracji elementów zielonych z budowlanymi ${ }^{13}$. Oddziaływanie wertykalnych systemów zieleni na prędkość wiatru bezpośrednio przy elewacji ma znaczenie głównie dla wychładzania przegród budynku i rozpatrywane jest przede wszystkim pod kątem zwiększenia termoizolacyjności przegród zewnętrznych i możliwych oszczędności z tytułu mniejszego zużycia energii na ogrzewanie obiektu ${ }^{14}$.

\section{Termoizolacja}

Introdukcja zieleni na fasady budynku poprawia parametry termoizolacyjne przegrody zewnętrznej. Struktura elewacji porośniętej pnączami zbliżona jest do ścian szczelinowych z izolacyjną termicznie warstwą powietrza (Celadyn, 1992). Wymierne korzyści można uzyskać w zależności od: wybranego systemu, jego

\footnotetext{
${ }^{12}$ Przeprowadzone badania na mało nasiąkliwych powierzchniach kamiennych wskazały na uskoki w elewacji jako na istotne źródło potencjalnych problemów z wodą. Nawet niewielkie elementy (do $10 \mathrm{~mm}$ ) sprzyjają miejscowemu zawilgoceniu ściany, zatrzymując wodę i jednocześnie utrudniając proces wysychania (Celadyn, 1992).

${ }^{13}$ Badania przeprowadzono w maksymalnej odległości $140 \mathrm{~cm}$ od ściany przy prędkości wiatru nieprzekraczającej $0,5 \mathrm{~m} \cdot \mathrm{s}^{-1}$. Zieleń bezpośrednio porastająca mur powoduje obniżenie prędkości wiatru w warstwie zielonego pokrycia o $0,43 \mathrm{~m} \cdot \mathrm{s}^{-1}$, w systemie pośrednim, przy szczelinie wentylacyjnej o szerokości $20 \mathrm{~cm}$ ta różnica wynosi $0,55 \mathrm{~m} \cdot \mathrm{s}^{-1}$, prędkość wiatru jednak wzrasta o $29 \mathrm{~m} \cdot \mathrm{s}^{-1}$ między pokryciem a ścianą. W systemie żyjącej ściany redukcja wynosi $0,46 \mathrm{~m} \cdot \mathrm{s}^{-1}$ (Perini i in., 2011b).

${ }^{14}$ Ochrona budynku przed wychłodzeniem przez wiatr może ograniczyć zużycie energii na ogrzewane o 25\% (Sheweka i Mohamed, 2012 za: Dinsdale, Pearen i Wilson, 2006).
} 
ekspozycji, parametrów tworzywa roślinnego (w tym wskaźnika $L A I$ ), grubości poszczególnych elementów, np. substratu, klimatu, warunków pogodowych. Dla jak najlepszej termoizolacyjności kluczowa jest introdukcja roślin o liściach całorocznych oraz zachowanie dystansu między elementami systemu o odpowiedniej szerokości. Najlepsze efekty w układach pośrednich można uzyskać, zapewniając szerokość szczeliny powietrznej nie większą niż 40-60 mm (Perini i in., 2011b). Na podstawie badań Perini i Rosasco (2013) stwierdzono, że opór cieplny warstwy roślinnej zarówno w układzie pośrednim, jak i bezpośrednim, wynikający $\mathrm{z}$ dodatkowej szczeliny powietrznej wynosi $0,09 \mathrm{~m}^{2} \cdot \mathrm{K} \cdot \mathrm{W}^{-1} \cdot \mathrm{W}$ systemie żyjącej ściany należałoby uwzględnić również pozostałe warstwy, w tym substrat. Ograniczenie strat ciepła $\mathrm{z}$ uwagi na zastosowanie zieleni na elewacjach wiąże się także $\mathrm{z}$ ochroną przed wymienionymi uprzednio czynnikami, tj. deszczem i wiatrem. Zapobieganie zamoknięciu powierzchni muru sprzyja zachowaniu lepszej izolacyjności, a zmniejszenie prędkości wiatru przy budynku wpływa na ograniczenie konwekcyjnych strat ciepła. Ponadto nie bez znaczenia jest czynnik czasu, gdyż wraz z jego upływem wzrastają termiczne właściwości systemu roślinno-architektonicznego dzięki rozrostowi i przyrostowi masy roślinnej. W świetle obowiązujących standardów w zakresie termoizolacyjności przegród zewnętrznych zieleń na elewacjach pozostaje jedynie elementem wspierającym zastosowane ocieplenie.

\section{Oddziaływanie chemiczne roślin}

Wpływ chemiczny roślin na powierzchnię ścian występuje w układach integrujących te dwa elementy, w zależności od gatunku roślin. Wbrew obiegowej opinii nie ma on jednak negatywnego wpływu na podłoże. Wydzielane przez pnącza kwasy organiczne lub inne związki chemiczne działają niezmiernie krótko, a dekstranowe substancje klejące przylg, np. winobluszczy, są nieszkodliwe dla powierzchni fasady (Borowski, 1996). Badania w Instytucie Techniki Budowlanej wykazały jedynie mikroubytki zaczynu cementowego i wapiennego w miejscu przywarcia przylg do podłoża tynkowego (Borowski, 1996).

\section{Ochrona przed hałasem}

Potencjał roślin również można wykorzystać do wzmocnienia izolacyjności akustycznej przegród zewnętrznych. Zieleń może wpłynąć na poziom hałasu na drodze trzech działań: odbicia i rozproszenia dźwięku, jego absorpcji oraz niszczącego zakłócania fali dźwiękowej. Ponadto wiele innych czynników ma wpływ na izolacyjność akustyczną zielonych ścian, tj.: wybrany system (bezpośredni, pośredni, żyjąca ściana), jego powierzchnia, użyte gatunki roślin, obecność substratu, jego rodzaj, grubość, nawet stopień nawodnienia, gęstość listowia itp. $Z$ tego powodu najbardziej korzystnym pod względem ochrony przed hałasem rozwiązaniem jest system żyjącej ściany. Jego wielowarstwowa budowa daje duże możliwości wpływu na poziom izolacji akustycznej przegrody zewnętrznej. Z dotychczas przeprowadzonych obserwacji roślinność na elewacjach redukuje natężenie dźwięku o 5-10 dB (Azkorra i in., 2015).

\section{PODSUMOWANIE}

Introdukcja roślin na ściany zewnętrzne budynku implikuje wiele różnych konsekwencji dla jego obudowy. Współpraca zieleni z architekturą może zaowocować wymiernymi korzyściami albo realnymi problemami. Z przeprowadzonej analizy, podsumowanej w tabeli 2, zyski dla budynku $\mathrm{z}$ tytułu wprowadzenia zieleni na jego elewacje przeważają straty. Główne korzyści dla budynku płynące $\mathrm{z}$ integracji roślin $\mathrm{z}$ elewacją wynikają z osłaniającej roli elementów zielonych przed czynnikami klimatycznymi, szczególnie przed oddziaływaniem promieniowania słonecznego. Ochraniająca funkcja roślinności w niektórych rozwiązaniach systemowych nie tylko wpływa na dłuższe zachowanie trwałości obudowy, ale ogranicza straty ciepła ściany zewnętrznej oraz obniża temperaturę jej powierzchni. Integracja zieleni i elewacji w przypadku bezpośredniego porastania muru przez pnącza może powodować problemy, prowadząc do naruszenia ciągłości warstwy zewnętrznej na skutek erozyjnego oddziaływania roślin. Najczęstszym powodem potencjalnych problemów jest jednak czynnik ludzki (błędy przy projektowaniu zielonych fasad, błędy wykonawcze, niedostateczna znajomość systemu roślinnego, brak pielęgnacji i konserwacji zieleni oraz konstrukcji wsporczych), stan techniczny zewnętrznych ścian budynku (liczne ubytki, pęknięcia na elewacji) oraz 
Tabela 2. Porównanie korzyści i zagrożeń dla budynku wynikających z wprowadzenia zieleni na elewacje (opracowanie własne)

Table 2. Comparison of benefits and menace to the building resulting from the introduction of greenery on the façade (own elaboration)

\begin{tabular}{|c|c|c|}
\hline $\begin{array}{l}\text { Obszary } \\
\text { problemowe } \\
\text { Problem areas }\end{array}$ & Zagrożenia-Menace & Korzyści - Profits \\
\hline $\begin{array}{l}\text { Woda deszczowa } \\
\text { Rainwater }\end{array}$ & $\begin{array}{l}\text { możliwe zawilgocenie ścian, szczególnie kiedy brakuje } \\
\text { osłaniających elementów, np. Gzymsów, i woda spływa } \\
\text { po elewacji wprost za warstwę zieleni porastającej jej } \\
\text { dolne partie - possible dampness of walls, especially } \\
\text { when there are no covering elements like cornices and } \\
\text { water flows down the façade directly behind the layer of } \\
\text { greenery growing on lower parts of the wall } \\
\text { możliwe utrudnienie wysychania powierzchni muru } \\
\text { okrytego zielenią w przypadku np. braku szczeliny } \\
\text { wentylacyjnej pomiędzy ścianą a roślinami - difficulties } \\
\text { in drying the wall surface covered with greenery in case } \\
\text { of, for example, lack of ventilation gap between the wall } \\
\text { and plants }\end{array}$ & $\begin{array}{l}\text { - osłona ściany przed zamoknięciem, co wpływa na } \\
\text { ograniczenie strat ciepła przez przegrodę zewnętrzną - wall } \\
\text { cover against waterlogging, which reduces heat loss through } \\
\text { the wall } \\
\text { - ochrona fasady przed kwaśnym deszczem, który może } \\
\text { przyczynić się do degradacji powłok elewacji - protection } \\
\text { of the facade against acid rain, which may contribute to } \\
\text { degradation of the facade coatings } \\
\text { - ochrona przed erozją muru spowodowaną naprzemiennym } \\
\text { zamakaniem i przesuszaniem jego powierzchni - protection } \\
\text { against wall erosion caused by alternating drying and } \\
\text { waterlogging it's surface } \\
\text { możliwość osuszania fundamentów - the possibility of } \\
\text { drying the foundations }\end{array}$ \\
\hline
\end{tabular}

- osłona muru przed bezpośrednim oddziaływaniem promieni słonecznych, a w konsekwencji redukcja temperatury powierzchni ściany - wall cover against direct sunlight and consequently reduction of wall surface temperature

Promieniowanie

słoneczne

Solar radiation

- ochrona ściany przed dobowymi wahaniami temperatury - wall protection against daily temperature fluctuations

- zmniejszenie naprężeń termicznych w przegrodzie pionowej - reduction of thermal stresses in the vertical partition

- ograniczenie zapotrzebowania energii na klimatyzację pomieszczeń w budynku - reducing the energy demand for air conditioning in the building

- uszkodzenia mechaniczne spowodowane przez ssanie wiatru, szczególnie w przypadku budynków wysokich lub wysokościowych - mechanical damage caused by wind suction, especially in high or high-rise buildings

Wiatr

Wind
- zmniejszenie prędkości wiatru przy elewacji - lowering the wind speed near the facade

- polepszenie izolacyjności termicznej ściany na skutek zmniejszenia wychładzania budynku przez wiatr - improving the thermal insulation of the wall as a result of reducing the cooling down of the building caused by the wind

- ograniczenie zapotrzebowania energii potrzebnej na ogrzewanie budynku - reducing the energy needed to heat the building

obniżenie poziomu natężenia dźwięku o 5-10 dB - lowering the sound intensity by $5-10 \mathrm{~dB}$

Noise

- obciążenie dla ściany i konstrukcji wsporczych - load for wall and supporting structures

- oddziaływanie mechaniczne sprzyjające deterioracji materiału, szczególnie w przypadku elewacji budynków o słabym stanie technicznym - mechanical impact favoring the deterioration of the material, especially in case of facades of buildings with poor technical condition

- możliwość uszkodzenia elementów zamocowanych do ścian, np. rur spustowych - possibility of damaging components attached to walls, e.g. drain pipes
- dodatkowa warstwa wspomagająca termoizolację pionowych przegród zewnętrznych - additional layer supporting thermal insulation of external vertical partitions 
upływ czasu.

Potencjał tkwiący w połączeniu natury $\mathrm{z}$ architekturą zależy od wielu czynników zarówno zaplanowanych, jak i niezamierzonych, które jednak można kontrolować lub zupełnie niezależnych. Jak wynika z zestawienia w tabeli 3, wiele czynników wpływających na odziaływanie zieleni na elewację można zaplanować na etapie projektowania, co może prowadzić nie tylko do zminimalizowania problemów związanych z późniejszą eksploatacją roślin na elewacjach, ale i wykorzystania ich atutów.

Rośliny jednocześnie wpływają na chemicznie i fizyczne parametry przegrody, stąd negatywny wpływ jednego oddziaływania może być rekompensowany korzyściami drugiego. Przykładowo ściana porośnięta w znacznym stopniu przez grubą warstwę bluszczu o wysokim wskaźniku $L A I$ zwiększy obciążenie przekazywane na przegrodę, ale za to będzie skuteczniej chroniła ją przed promieniowaniem słonecznym. Rozważanie możliwych problemów i korzyści związanych $\mathrm{z}$ zielenią na elewacjach z pewnością wymaga pewnego kompromisu i uważnego wyboru parametrów, np. sposobu integracji. Kluczowe jest też analiza zasadności i efektywności projektowanej zielonej ściany w odniesieniu do zastanej lokalizacji oraz panujących warunków mikroklimatycznych miejsca, np. zacienie czy spotęgowana przez otaczającą zabudowę prędkość wiatru mogą w znacznym stopniu wpłynąc na stan roślin pokrywających elewację. W różnych strefach klimatycznych rozwiązania wertykalnych systemów zieleni różnią się szczególnie w zakresie stosowanej roślinności, a w przypadku LWS również i medium.

Tabela 3. Przyporządkowanie czynników wpływających na skalę oddziaływania roślin na budynek według możliwości ich kontroli i zaplanowania (opracowanie własne)

Table 3. Assignment of factors affecting the scale of plant impact on the building according to the possibilities of their control and planning (own elaboration)

\begin{tabular}{|c|c|}
\hline $\begin{array}{l}\text { Zaplanowane } \\
\text { Intended }\end{array}$ & $\begin{array}{l}\text { - wybór sposobu integracji roślin z budynkiem - selection of plant integration measures with the building } \\
\text { - wybór instalacji nawadniającej, substratu w systemie żyjącej ściany - selection of irrigation installation, substrate } \\
\text { in the LWS } \\
\text { - dobór roślin, także ich wieku, rozmiaru - selection of plants, also their age, size } \\
\text { - zaprojektowanie konstrukcji wsporczych, w tym zaplanowanie odległości od przegrody budynku - design of } \\
\text { supporting structures, including planning the distance from the building envelope } \\
\text { - ukształtowanie architektoniczne elewacji (wnęki, uskoki, gzymsy itp.) - architectural shape of the facade (recesses, } \\
\text { stepped cornices etc.) } \\
\text { - rozwiązania materiałowe obudowy zewnętrznej budynku (materiał wykończeniowy) - material solutions for the } \\
\text { external building envelope (finishing material) } \\
\text { - wybór ekspozycji zielonej fasady - selection of the green facade exhibition } \\
\text { - stopień pokrycia ściany zielenią w systemie żyjącej ściany, w układach pośrednich - degree of covering the wall with } \\
\text { greenery in the LWS, in indirect systems } \\
\text { - stopień integracji zieleni z powierzchnią muru (system bezpośredni, pośredni, żyjąca ściana) - degree of integration } \\
\text { of greenery with the wall surface (direct system, indirect, living wall) }\end{array}$ \\
\hline $\begin{array}{l}\text { Niezamierzone/ } \\
\text { /możliwe do } \\
\text { kontrolowania } \\
\text { Possible to control }\end{array}$ & $\begin{array}{l}\text { - ekspansja wzrostowa roślin (ograniczona w systemie bezpośrednim) - plant growth expansion (limited in the direct } \\
\text { system) } \\
\text { - pielęgnacja roślin (choroby i szkodniki) - plant care (diseases and pests) } \\
\text { - stan techniczny elewacji budynku - technical condition of the building's elevation }\end{array}$ \\
\hline $\begin{array}{l}\text { Nieprzewidywalne/ } \\
\text { /niezależne } \\
\text { Unpredictable }\end{array}$ & $\begin{array}{l}\text { - warunki klimatyczne, mikroklimatyczne danej lokalizacji - climatic and microclimatic conditions of given location } \\
\text { - reakcja roślin na lokalne warunki środowiska (klimat, wilgotność i stopień zanieczyszczenia powietrza) - reaction } \\
\text { of plants to local environmental conditions (climate, humidity and degree of air pollution) } \\
\text { niektóre parametry szaty roślinnej: gęstość i zwartość pokrywy, powierzchnia pokrycia fasady, w tym stopień jej } \\
\text { równomiernego lub nie porośnięcia - some parameters of vegetation: thickness and compactness of the cover, the } \\
\text { surface of the greenery cover, including the level of it's uniform or non-overgrowing }\end{array}$ \\
\hline
\end{tabular}


Przy czym zielone ściany jako ochrona przed nadmierną insolacją sprawdzają się na obszarach o wysokiej temperaturze, np. w klimacie śródziemnomorskim. Wyzwanie stanowić mogą natomiast systemy żyjących ścian, np. w klimacie umiarkowanym przejściowym, w którym kluczowy jest dobór gatunków roślin przystosowanych do zmian temperatur oraz grubość i skład medium. Obecnie różnorodność oferowanych rozwiązań systemowych daje możliwość dopasowania wymagań zieleni do niesprzyjających warunków panujących w środowisku zurbanizowanym, jak np. w realizacji Jeana Nouvela One Central Park w Sydney, gdzie żyjąca ściana oraz pnącza porastają wysoką na ponad $110 \mathrm{~m}$ elewację.

Mimo rozwoju systemów nadal głównym wyzwaniem pozostaje element roślinny. Rozwiązania zastosowane w żyjących ścianach znacznie ograniczyły potencjalne zagrożenia dla trwałości przegród ze strony zieleni, wymagaja jednak większych nakładów energii, a także środków finansowych związanych z utrzymaniem optymalnego stanu szaty roślinnej, szczególnie w trudnych dla natury warunkach miejskiego klimatu w strefie umiarkowanej. Stąd najlepsze efekty można osiągnąć, stosując rodzime gatunki roślin przystosowane do warunków klimatycznych oraz dobór odpowiedniego medium w przypadku żyjących ścian. Ponadto projektowanie zielonych elewacji powinno mieć charakter interdyscyplinarny, w którym dobór roślinności, systemu nawadniającego, a także rodzaj medium należy powierzyć botanikom oraz wyspecjalizowanym wykonawcom.

Wprowadzenie roślin na elewacje budynku wciąż rodzi wiele komplikacji, ale jak wskazują przeprowadzone badania, z których część przywołano w niniejszym artykule, warto podjąć to wyzwanie. Beneficjentami korzyści płynących z zastosowania wertykalnych systemów zieleni na terenach silnie zurbanizowanych są budynki, ale również ich użytkownicy oraz przestrzeń miejska, którą te obiekty kształtują.

\section{PIŚMIENNICTWO}

Azkorra, Z., Pérez, G., Coma, J., Cabeza, L. F., Bures, S., Álvaro, J. E., Erkoreka, A. i Urrestarazu, M. (2015). Evaluation of green walls as passive acoustic insulation system for buildings. Applied Acoustic, 89, 46-56. doi: 10.1016/j.apacoust.2014.09.010
Barnaś, K. (2011). Elewacje zielone - nowoczesne technologie w projektowaniu i wykonawstwie. Czasopismo Techniczne. Architektura, 108 (2-A/2), 7-13. Pobrano z lokalizacji: http://suw.biblos.pk.edu.pl/search\&query=barnaś\&termId $=1,2,79 \&$ order $=3,1 \quad($ dostęp 10.04.2018).

Bartnicka, M. i Ullman, I. (2009). Wykorzystać wszystkie atuty zieleni. Architecturae Et Artibus, 1 (2), 17-22. Pobrano z lokalizacji: http://yadda.icm.edu.pl/yadda/ element/bwmeta1.element.baztech-article-BPB1-00430003 (dostęp 28.02.2018).

Borowski, J. (1996). Pnącza w warunkach miejskich. Pobrano z lokalizacji: www.zszp.pl/pliki/ZWKpnaczaWK.pdf (dostęp 13.06.2018).

Celadyn, W. (1992). Architektura a systemy roślinne. Kraków: Politechnika Krakowska.

Cuce, E. (2017). Thermal regulation impact of green walls: An experimental and numerical investigation. Applied Energy, 134, 247-254. doi: 0.1016/j.apenergy.2016.09.079

Hoelscher, M-T., Nehls, T., Jänicke, B. i Wessolek, G. (2016). Quantifying cooling effects of façade greening: Shading, transpiration and insulation. Energy and Buildings, 114, 283-290. doi: www.sciencedirect.com/science/article/pii/S0378778815300761?via\%3Dihub

Kowalczyk, A. (2011). Zielone dachy szansą na zrównoważony rozwój terenów zurbanizowanych. Zrównoważony Rozwój-Zastosowania, 2, 66-81. Pobrano z lokalizacji: http://sendzimir.org.pl/images/ZR_2/5_PL.pdf (dostęp 08.05.2018).

Manso, M. i Castro-Gomes, J. P. (2015). Green wall systems: A review of their characteristics. Renewable and sustainable Energy Reviews, 41, 863-871. doi: 10.1016/ j.rser.2014.07.203

Pérez, G., Coma, J., Martorell, I. i Cabeza, L. F. (2014). Vertical Greenery Systems (VGS) for Energy saving in buildings: A review. Renewable and Sustainable Energy Reviews, 39, 139-165. doi: 10.1016/j.rser.2014.07.055

Perini, K. i Rosasco, P. (2013). Cost-benefit analysis for green facades and living wall systems. Building and Environment, 70, 110-121. doi: 10.1016/ j.buildenv.2013.08.012

Perini, K., Ottelé, M., Fraaij, A. L. A., Haas, E. M. i Raiteri, R. (2011b). Vertical greening systems and the effect on air flow and temperature on the building envelope. $\mathrm{Bu}$ ilding and Environment, 46, 2287-2294. doi: 10.1016/ j.buildenv.2011.05.009

Perini, K., Ottelé, M., Haas, E. M. i Raiteri, R. (2011a). Greening the building envelope, facade greening and living wall systems. Open Journal of Ecology, 1 (1), 1-8. doi: 10.4236/oje.2011.11001 
Safikhani, T., Abdullah, A. M., Ossen, D. R. i Baharvand, M. (2014). Thermal Impacts of Vertical Greenery Systems. Environmental and Climatic Technologies, 14, 5-11. doi: 10.1515/rtuect-2014-0007

Sheweka, S. M. i Mohamed, N. M. (2012). Green Facades as a New Sustainable Approach Towards Climate Change. Energy Procedia, 18, 507-520. doi: 10.1016/j.egypro.2012.05.062

Skorupski, W. (1984). Wyniki badań nad składem powietrza atmosferycznego na terenach zieleni i ulicach miejskich w Warszawie. W H. B. Szczepanowska (red.), Wpływ zieleni na kształtowanie środowiska miejskiego (strony 95-108). Warszawa: Państwowe Wydawnictwo Naukowe.

Sternberg, T., Viles, H. i Cathersides, A. (2011). Evaluating the role of ivy (Hedera helix) in moderating wall surface microclimates and contributing to the bioprotection of historic buildings. Building and Environment, 46 (2), 293-297. doi: 10.1016/j.buildenv.2010.07.017

Susorova, I., Angulo, M., Bahrami, P. i Stephens, B. (2013). A model of vegetated exterior facades for evaluation of wall thermal performance. Building and Environment, 67, 1-13. Pobrano z lokalizacji: built-envi.com/publications/susorova_etal_be_2013.pdf (dostęp 11.04.2018).

Szczepanowska, H. B. (2012). Miejsce terenów zieleni w strukturze zintegrowanego projektowania, zarządzania i oceny ekologicznej inwestycji miejskich. Człowiek i Środowisko, 36 (1-2), 25-49.

Trzaskowska, E. (2010). Wykorzystanie roślin w projektowaniu architektonicznym (pnącza, ogrody wertykalne). Teka Komisji Architektury, Urbanistyki i Studiów Krajobrazowych O.L. PAN, 110-121. Pobrano z lokalizacji: http://www.pan-ol.lublin.pl/wydawnictwa/TArch6/ Trzaskowska_1.pdf (dostęp 17.04.2018).

Zinowiec-Cieplik, K. (2017). Potencjał integracji form roślinnych z architekturą - środowisko i technika. Kwartalnik Naukowy Uczelni Vistula, 4 (54), 128-141. Pobrano z: yadda.icm.edu.pl/yadda/element/bwmeta1.element.desklight-849151b5-c895-436c-a522-c755d05a3262?q=bwmeta1.element.desklight-726a562f-aeb94a57-aa5d-f38b0f1a406f;11\&qt=CHILDREN-STATELESS (dostęp 29.01.2018).

\title{
GREENERY ON FACADES - A PROBLEM OR A BENEFIT FOR BUILDINGS?
}

\begin{abstract}
Greenery on elevations, despite it's growing popularity, still raises many doubts about the consequences of it's impact on the walls. Are the plants covering the façade a growing problem or a support for building through nature? This article presents and analyzes the benefits as well as problems resulting from the combination of architecture with nature and assesses the consequence of it's application for the building. The considerations refer to commonly used methods of plant integration with elevations (direct system, indirect system and Living Walls System), which were analyzed in terms of two types of impact: physical and chemical. The review indicated numerous benefits for the building resulting from the use of greenery including: minimized heat loss, increased durability of the elevations or lowering heat stresses in vertical partition. Inspite of potential problems resulting mainly from the erosive action of climbing plants growing on the walls and the risk of moistening sheltered elements, greenery is an added value to the building.
\end{abstract}

Key words: greenery, vertical greenery systems, green elevations, plants and buildings, green walls 